\title{
OPEN An optimized desuccinylase activity assay reveals a difference in desuccinylation activity between proliferative and differentiated cells
}

\begin{abstract}
Taolin Yuan $\mathbb{D}^{1}$, Jaap Keijer ${ }^{1}{ }^{1}$, Angela H. Guo ${ }^{2}$, David B. Lombard² \& Vincent C. J. de Boer $\mathbb{D}^{1 \bowtie}$
Succinylation is a novel post-translational modification identified on many proteins and is involved in multiple biological processes. Succinylation levels are dynamically regulated, balanced by succinylation and desuccinylation processes, and are closely connected to metabolic state in vivo. Sirtuins have been shown to possess $\mathrm{NAD}^{+}$-dependent desuccinylation activity in vitro and in vivo, among which the desuccinylation activity of SIRT5 is most extensively studied. Our understanding of the response of succinylation levels to different metabolic conditions, is hampered by the lack of a fast $\mathrm{NAD}^{+}$-dependent desuccinylation assay in a physiological context. In the present study, we therefore optimized and validated a fluorescence-based assay for measuring NAD+-dependent desuccinylation activity in cell lysates. Our results demonstrated that shorter and stricter reaction time was critical to approach the initial rate of $\mathrm{NAD}^{+}$-dependent desuccinylation activity in crude cell lysate systems, as compared to the desuccinylation reaction of purified His-SIRT5. Analysis of desuccinylation activity in SIRT5 knockout HEK293T cells confirmed the relevance of SIRT5 in cellular desuccinylation activity, as well as the presence of other $\mathrm{NAD}^{+}$-dependent desuccinylase activities. In addition, we were able to analyse desuccinylation and deacetylation activity in multiple cell lines using this assay. We showed a remarkably higher desuccinylase activity, but not deacetylase activity, in proliferative cultured muscle and adipose cells in comparison with their differentiated counterparts. Our results reveal an alteration in $\mathrm{NAD}^{+}$-dependent desuccinylation activity under different metabolic states.
\end{abstract}

Proteins involved in almost all essential life processes undergo different post-translational modifications (PTMs), by which protein structural changes are introduced and the functionality of the proteome is diversified ${ }^{1-3}$. Posttranslational modifications are closely associated with metabolites ${ }^{4-6}$, and the intimate connection between PTMs and metabolites allow PTMs to integrate different signals to enable rapid responses of the organism to environmental challenges ${ }^{7}$. Lysine succinylation is a relatively new PTM, identified nearly one decade ago ${ }^{1}$. It provides a dynamic and relatively abundant network of modifications on both mitochondrial and extra-mitochondrial proteins $s^{1,8-10}$. Lysine residues of many proteins involved in important metabolic processes, such as fatty acid $\beta$-oxidation, ketogenesis, tricarboxylic acid (TCA) cycle, branched chain amino acids metabolism, and glycolysis/gluconeogenesis, are subjected to succinylation ${ }^{11-16}$. In addition, protein succinylation levels respond to metabolic manipulations. For example, succinylation levels in whole-cell extracts and mitochondria in mouse liver were increased under a fasting condition ${ }^{11}$. In contrast, mouse liver succinylation levels were shown to be significantly decreased ${ }^{17}$ or variably altered ${ }^{18}$ by a high fat diet intervention. These results indicate that protein succinylation levels vary with metabolic contexts and are likely to play a role in various signaling processes and regulatory pathways. Therefore, succinylation levels need to be carefully controlled. Sirtuins, a family of nicotinamide adenine dinucleotide $\left(\mathrm{NAD}^{+}\right)$-dependent lysine deacylase, regulate acylation levels in vivo ${ }^{19-23}$. Thus far, sirtuin (SIRT) 5 and SIRT7 have been shown to be able to remove a succinyl adduct from lysine in the

${ }^{1}$ Human and Animal Physiology, Wageningen University \& Research, Wageningen 6708 WD, The Netherlands. ${ }^{2}$ Department of Pathology, University of Michigan, Ann Arbor, MI 48109, USA. ${ }^{\square}$ email: vincent.deboer@wur.nl 
presence of the cofactor NAD ${ }^{+24,25}$. SIRT5 was identified as a robust desuccinylase ${ }^{24}$, but it can also remove malonyl and glutaryl adducts from lysine residues with high affinity ${ }^{24,26}$ and possesses a weak deacetylase activity ${ }^{27}$. SIRT7 was demonstrated to function as a histone desuccinylase ${ }^{25}$, and is also able to remove acetyl-group from $\operatorname{targets}^{28,29}$. Since the protein succinylation level can be driven by succinyl-CoA levels ${ }^{5,8,30}$, as well as NAD ${ }^{+}$levels or the $\mathrm{NAD}^{+} / \mathrm{NADH}$ balance ${ }^{31}$, it is likely that ultimately a complex interplay between succinyl-CoA, NAD ${ }^{+}$ and desuccinylase activity dictates lysine succinylation levels ${ }^{15,16}$. Although changes in succinylation levels have been observed with altered metabolism, it is not completely understood how desuccinylation activity responds to metabolic alterations. Improved understanding would be facilitated by the availability of additional options to assay desuccinylase activity.

A fluorescence based, homogenous, $\mathrm{NAD}^{+}$-dependent desuccinylation activity assay to study desuccinylase activity in crude cell lysate directly and rapidly is lacking. Its availability would allow for studying desuccinylation in a physiological context. Fluorogenic assays have been used for identifying activators and inhibitors of recombinant SIRT5 in vitro ${ }^{32-34}$. Only a limited number of studies analysed desuccinylase activity in the more physiological context of a cell lysate ${ }^{35,36}$. Notably, $\mathrm{NAD}^{+}$-dependent desuccinylase activity in a crude cellular extract has not yet been reported to our knowledge. Here, we optimize and validate a fluorescence-based assay for detecting $\mathrm{NAD}^{+}$-dependent cellular desuccinylase activity. Moreover, we use this assay to gain insights into $\mathrm{NAD}^{+}$-dependent desuccinylase activity in different cellular contexts, as well as its relation to global protein succinylation levels.

\section{Results}

Optimization and validation of desuccinylation activity in crude cell lysate. We aimed to measure cellular $\mathrm{NAD}^{+}$-dependent desuccinylase activity by using the succinylated-fluorogenic reporter substrate (Fig. 1a). Given the complexity of enzymatic reactions in crude cell lysates, we first optimized and validated the assay with a pure recombinant $\mathrm{NAD}^{+}$-dependent desuccinylase protein, His-SIRT5. Levels of desuccinylated peptides increased linearly over time up to $2 \mathrm{~h}$ (Fig. 1b), when incubating His-SIRT5 with $10 \mu \mathrm{M}$ succinyl-substrate and $500 \mu \mathrm{M} \mathrm{NAD}^{+}$. In addition, the desuccinylation rate of the peptide substrate linearly increased with the His-SIRT5 input when the reaction time was fixed (Fig. 1c). In contrast to the substantial desuccinylation activity of His-SIRT5, its deacetylation activity was virtually undetectable (Fig. 1d). In addition, we performed the assay in the presence of nicotinamide (NAM), a well-known inhibitor of sirtuins. As expected, the desuccinylation activity of His-SIRT5 was negatively impacted by NAM, with an $\mathrm{IC}_{50}$ value of $20.2 \mu \mathrm{M}$ (Fig. 1e). These results showed that $\mathrm{NAD}^{+}$-dependent desuccinylation activity of His-SIRT5 can be analysed well using the succinylated-fluorogenic reporter substrate. We next examined whether the assay set-up for pure His-SIRT5 could be applied to measure desuccinylase activity in a crude cell lysate. Linearity of cellular desuccinylation activity with time was assessed in fibroblasts cell lysates. Desuccinylation of the succinylated-substrate was proportional to reaction time up to $15 \mathrm{~min}$, after which the reaction rate decreased (Fig. 2a), suggesting that an initial reaction rate was reached in the first $15 \mathrm{~min}$. After $15 \mathrm{~min}$, desuccinylated adduct amount again increased linearly with time, but at a slower reaction rate. Based on this, we performed further analyses of desuccinylase activity after $10 \mathrm{~min}$, i.e. within the first $15 \mathrm{~min}$. Desuccinylation by cell lysate after $10 \mathrm{~min}$ reaction time increased linearly in a protein-dependent manner (Fig. 2b). Inhibition by NAM of the cellular desuccinylation activity was observed at concentrations higher than $0.1 \mathrm{mM}$, and maximal inhibition was seen at $2 \mathrm{mM}$ (Fig. 2c). Moreover, the desuccinylase activity was lower in HEK293T SIRT5 knockout cell lysates as compared to wild type cell lysates at all tested reaction time, which ranged from 2.5 to $60 \mathrm{~min}$ (Fig. 2d). This result demonstrates that SIRT5 contributes to the desuccinylation activity of the crude cell lysate. Of note, the level of desuccinylated adduct increased over time in the absence of SIRT5 (Fig. 2d), indicating the presence of multiple desuccinylation enzymes in the crude cell lysate. Taken together, our results show that cellular desuccinylation activity can be analysed by the fluorescence-based assay, is dependent on $\mathrm{NAD}^{+}$and is sensitive to NAM inhibition.

Desuccinylation and deacetylation activities in a range of cells with diverse metabolic states. Cellular succinylation levels were shown to be dynamically affected by metabolism ${ }^{8}$, whereas little is known about $\mathrm{NAD}^{+}$-dependent desuccinylation activity in cells with variable metabolic states. To gain insights into the latter, we analysed the desuccinylation activity by applying the fluorescence-based assay in a variety of cell lines that are commonly used. Desuccinylation activities among the different cell lines ranged from 0.0018 to $0.003 \mathrm{pmol} / \mathrm{min} / \mu \mathrm{g}$ protein (Fig. 3a), whereas the deacetylation activities in the same cell lines were approximately tenfold higher (Fig. 3b). Interestingly, desuccinylation activity among the tested cell lines did not differ markedly, whereas differences in the deacetylase activity appeared to larger between the cell types. The deacetylation activity was highest in Caco 2 cells and lowest in fibroblasts (Fig. 3b).

A difference in desuccinylation activity between proliferative and differentiated cells. Next, we asked whether cellular differentiation alters desuccinylase activity. In myoblasts differentiated into myotubes, metabolic changes occur with a relative increase in mitochondrial mass ${ }^{37,38}$. Furthermore, differentiation of preadipocytes to adipocytes results in lipid droplets formation and a relative increase in mitochondrial biogenesis and metabolism ${ }^{39,40}$. Since SIRT5 is mainly localized in mitochondria, and acylations such as acetylation has been shown to be involved in cell differentiation ${ }^{41,42}$, desuccinylase activity could play a role in differentiation as well. C2C12 mouse myoblasts were successfully differentiated into myotubes, as can be seen from the longer myotubular structures that were observed after differentiation (Fig. 4a). Also, 3T3-L1 mouse preadipocytes were successfully differentiated into adipocytes, as can be seen from the lipid droplet accumulation in the cytosol of the adipocytes (Fig. 4b). Interestingly, desuccinylation activity in myotubes was around fourfold $(\mathrm{P}=0.0002)$ lower than in the myoblasts (Fig. 4c) and desuccinylase activity in adipocytes was around sixfold $(\mathrm{P}=0.0375)$ 


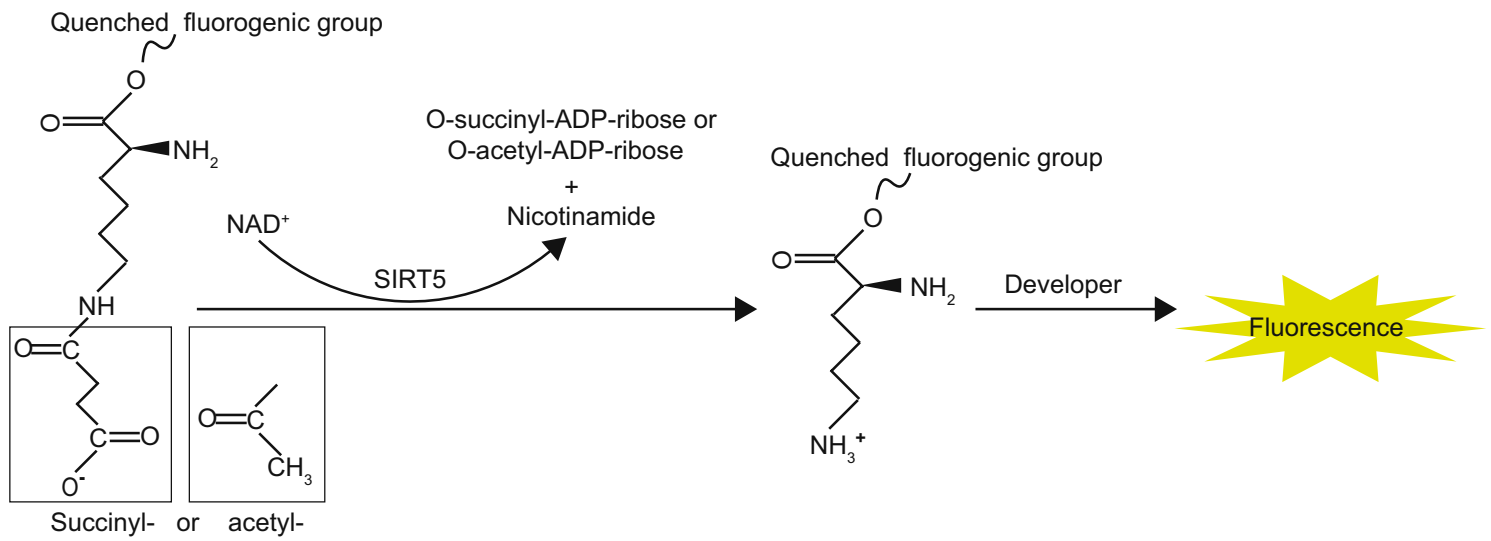

b

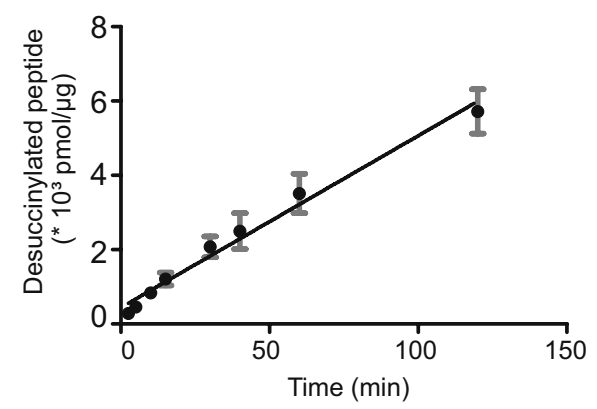

d

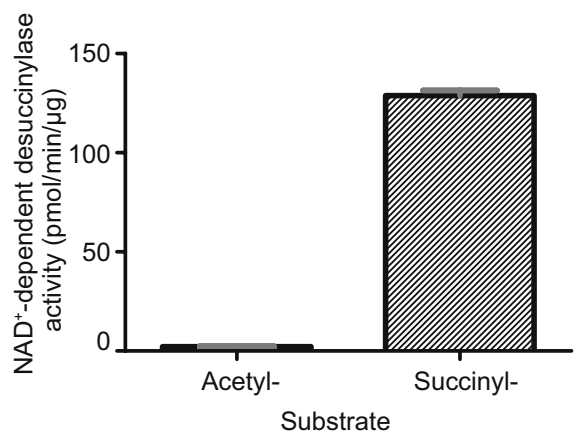

C

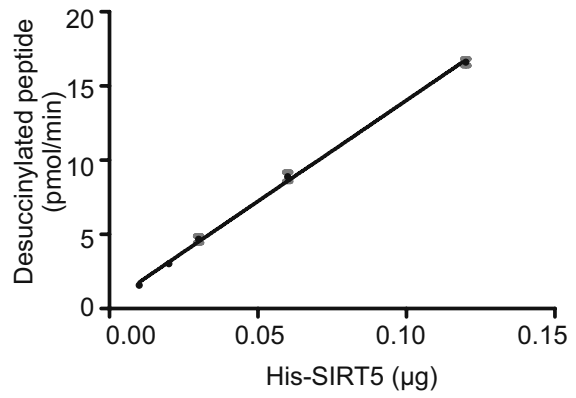

e

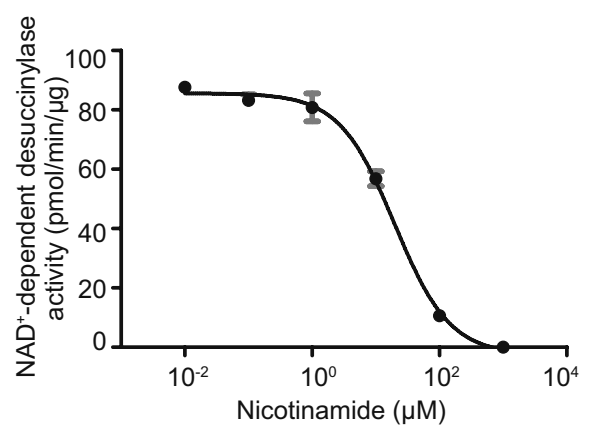

Figure 1. $\mathrm{NAD}^{+}$-dependent deacylation activity of human His-SIRT5. (a) Schematic illustration of desuccinylation and deacetylation activity analysis using a fluorogenic reporter assay. (b) Time course $\mathrm{NAD}^{+}$dependent desuccinylation of succinylated-substrate by His-SIRT5 $(0.046 \mu \mathrm{g})$. The desuccinylation reaction was proceeded for 2.5-120 min. Data represent mean $\pm \mathrm{SEM}, \mathrm{n}=3$. (c) $\mathrm{NAD}^{+}$-dependent desuccinylation of succinylated-substrate by increasing His-SIRT5 input $(0.03-0.12 \mu \mathrm{g})$. (d) $\mathrm{NAD}^{+}$-dependent deacetylation (left) and desuccinylation activity (right) of His-SIRT5 $(0.03 \mu \mathrm{g})$. (e) Inhibition of $\mathrm{NAD}^{+}$-dependent desuccinylation activity of His-SIRT5 $(0.06 \mu \mathrm{g})$ by nicotinamide. (b-e), fluorescence signal obtained in the negative group (with cell lysates and with acylated-substrate and without $\mathrm{NAD}^{+}$) was subtracted from each experiment. Error bars in (c-e) represent deviation from the mean of duplicates.

lower than that in the preadipocytes (Fig. $4 \mathrm{~d}$ ). In contrast, NAD ${ }^{+}$-dependent deacetylase activity displayed comparable in myotubes and adipocytes as compared to that in myoblast and preadipocytes, respectively (Fig. 4e,f). Given that the observed $\mathrm{NAD}^{+}$-dependent desuccinylation activities in myotubes and adipocytes were much lower than that in their proliferative counterparts, we aimed to study whether this was reflected in the SIRT5 protein levels. Since mitochondrial biogenesis is closely associated with cell differentiation, and SIRT5 is known to be the non-redundant desuccinylase in mitochondria. We first analysed the expression level of the mitochondrial outer membrane protein, voltage-dependent anion channel (VDAC). As expected, protein levels of VDAC (normalised to histone3 level) were increased by around fourfold in both myotubes and adipocytes (Fig. 5a). Unexpectedly, the SIRT5 protein levels (normalised to histone3 level) in myotubes and adipocytes were 
a

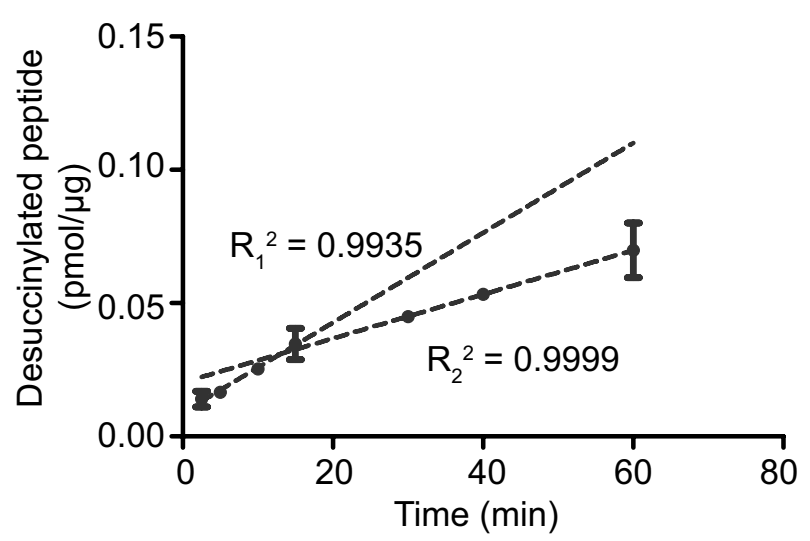

C

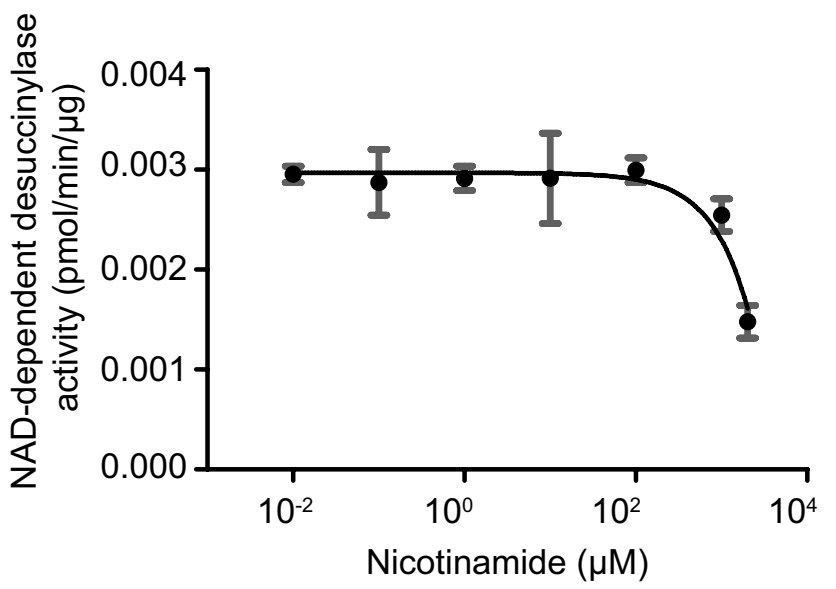

b
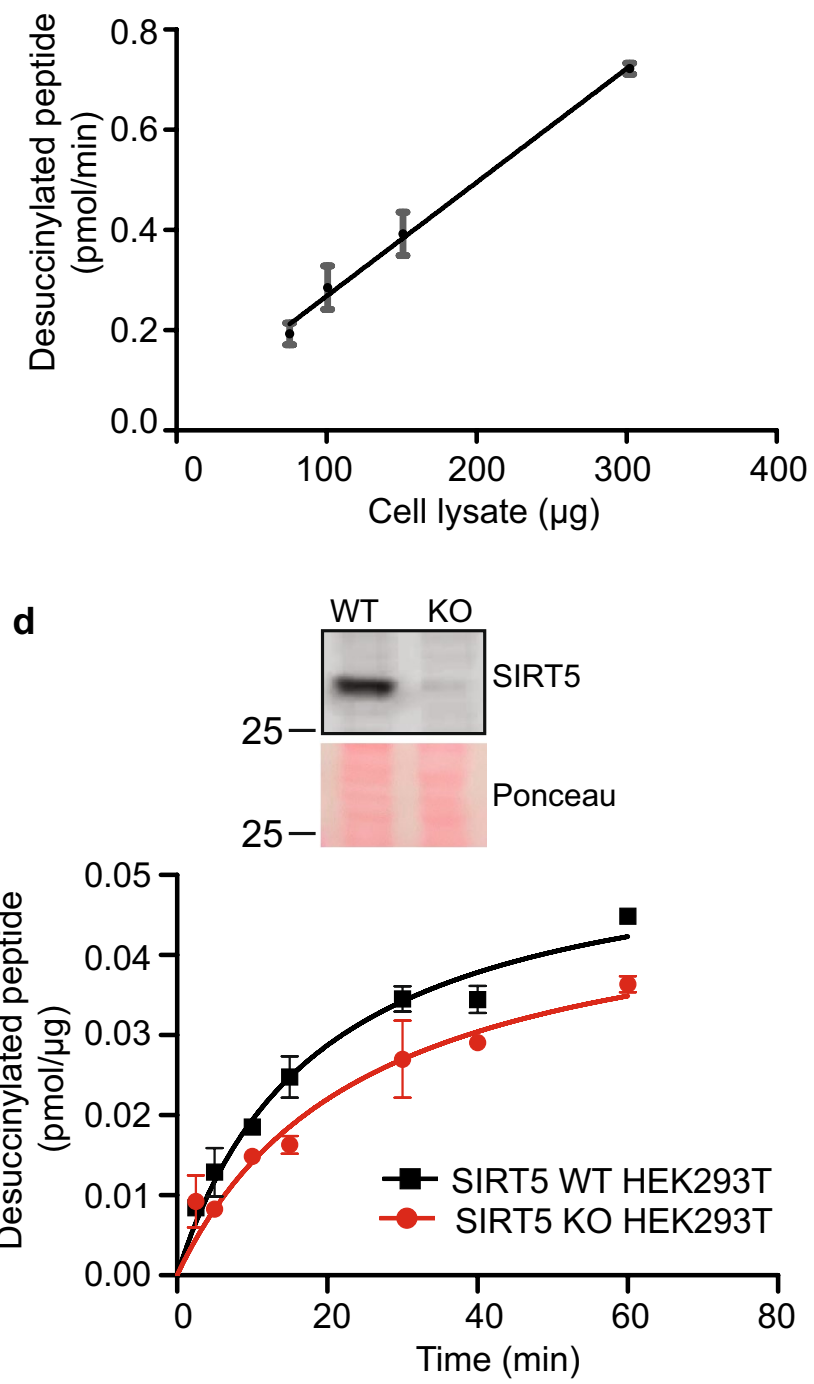

Figure 2. $\mathrm{NAD}^{+}$-dependent desuccinylation activity in human fibroblast lysate. (a) Time course $\mathrm{NAD}^{+}$dependent desuccinylation of succinylated-substrate by cell lysate $(148.5 \mu \mathrm{g})$. The desuccinylation reaction was proceeded for 2.5-60 min. Two dashed lines represent two different slopes obtained from the first four data points and last three data points, respectively. (b) $\mathrm{NAD}^{+}$-dependent desuccinylation of succinylatedsubstrate by increasing fibroblasts lysate $(75.5-302 \mu \mathrm{g})$. (c) Inhibition of NAD ${ }^{+}$-dependent desuccinylation activity of fibroblasts lysate $(187.3 \mu \mathrm{g})$ by nicotinamide. (d) Time-course $\mathrm{NAD}^{+}$-dependent desuccinylation of succinylated-substrate by SIRT5 WT $(140 \mu \mathrm{g})$ and SIRT5 KO $(140 \mu \mathrm{g})$ HEK293T cell lysate, respectively. Blots of SIRT5 and ponceau staining were cropped from the same blot, and the full-length SIRT5 blot and the ponceau image are presented in Supplementary Fig. 2. (a-d) Fluorescence signal obtained in the presence of substrate and absence of $\mathrm{NAD}^{+}$was subtracted from each experiment sample. Experiments were done in duplicates, and error bars represent deviation from the mean.

increased by twofold as compared to their proliferative counterparts (Fig. 5a). Since total desuccinylase activity decreased (Fig. 4c,d) and SIRT5 protein levels increased, we were interested to see how it was reflected in the protein lysine succinylation levels of undifferentiated and differentiated myocytes and adipocytes. Our results show a distinct pattern of lysine succinylation for each cell type (Fig. 5b,c). Band intensity lane profiling of succinylated proteins on blots showed multiple bands with a higher intensity in the myoblasts compared to myotubes (grey areas in Fig. 5b), indicating that higher lysine succinylation levels of these proteins in myoblasts. However, other protein bands were of lower intensity in the myoblasts as compared to the same bands in the myotubes (green areas, Fig. 5b), indicating that lower succinylation levels of these proteins in myoblasts as compared to myotubes. Also when comparing succinylation profiles between preadipocytes and adipocytes, succinylation differences similar to those seen in the muscle cell were observed, with multiple protein bands being of higher intensity in preadipocytes as compared to adipocytes (grey areas, Fig. 5c), while this was the other way around for other proteins (red areas, Fig. 5c). Taken together, in differentiated myotubes and adipocytes, the overall 
a

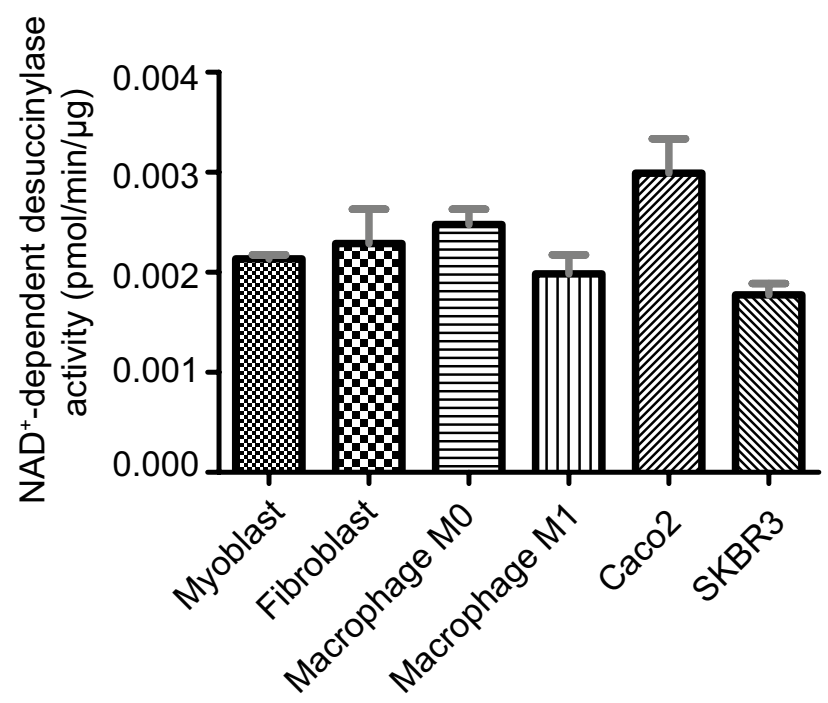

b

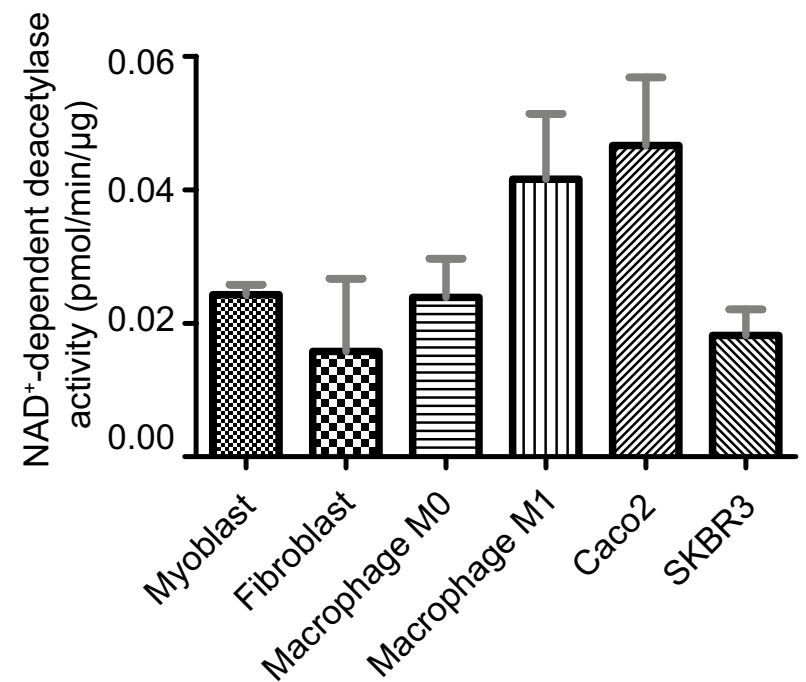

Figure 3. $\mathrm{NAD}^{+}$-dependent deacylation activities in various cell lines. (a) $\mathrm{NAD}^{+}$-dependent desuccinylase activity, and (b) $\mathrm{NAD}^{+}$-dependent deacetylase activity in multiple cell lines. $200 \mu \mathrm{g}$ of cell lysates, $10 \mu \mathrm{M}$ of succinyl/acetyl-substrate and $500 \mu \mathrm{M} \mathrm{NAD}^{+}$were present in the desuccinylation/deacetylation assays. Fluorescence signal obtained in the presence of substrate and absence of $\mathrm{NAD}^{+}$was subtracted from each experiment sample. Experiments were done in duplicates, and error bars represent deviation from the mean.

desuccinylation activity was decreased, the SIRT5 protein level was increased and protein lysine succinylation profiles changed differentially.

\section{Discussion}

The complex interplay between metabolite-driven succinylation and $\mathrm{NAD}^{+}$-dependent desuccinylation gives opportunities to cells to regulate protein function based on metabolic state of the cells. To get more insights into these processes, we optimized a desuccinylase assay in cell lysates and applied our method to different cell types and conditions. We showed that a stricter reaction time was required to analyse initial rate in crude cell lysates as compared to recombinant His-SIRT5, that SIRT5 was responsible partially for the observed $\mathrm{NAD}^{+}$-dependent desuccinylase activity, and that $\mathrm{NAD}^{+}$-dependent desuccinylation activity varied with physiologic states. $\mathrm{NAD}^{+}$-dependent desuccinylase activity was higher in proliferative myoblasts and preadipocytes as compared to their differentiated counterparts. 
a
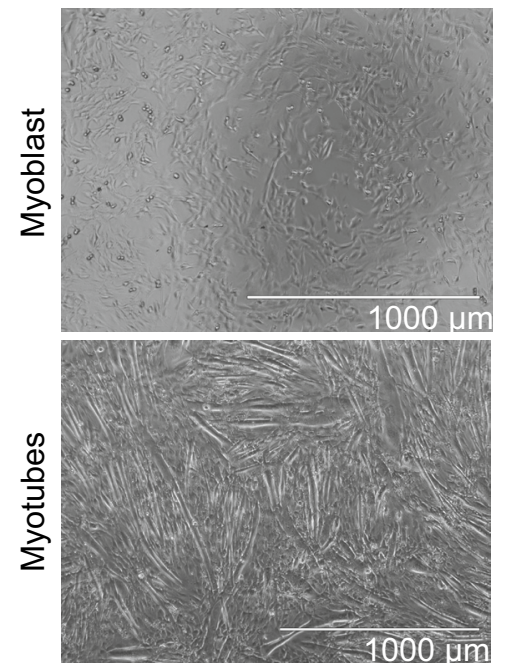

C

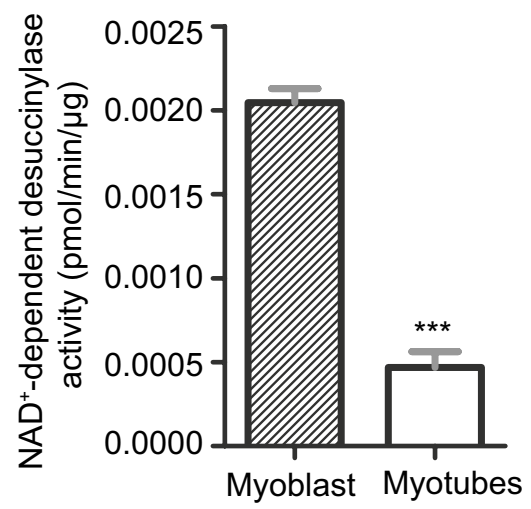

e

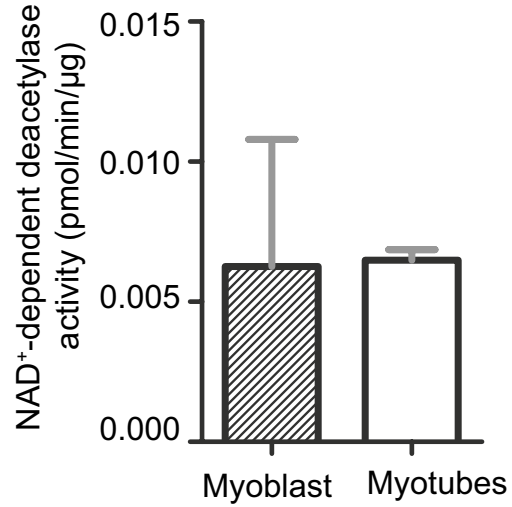

b
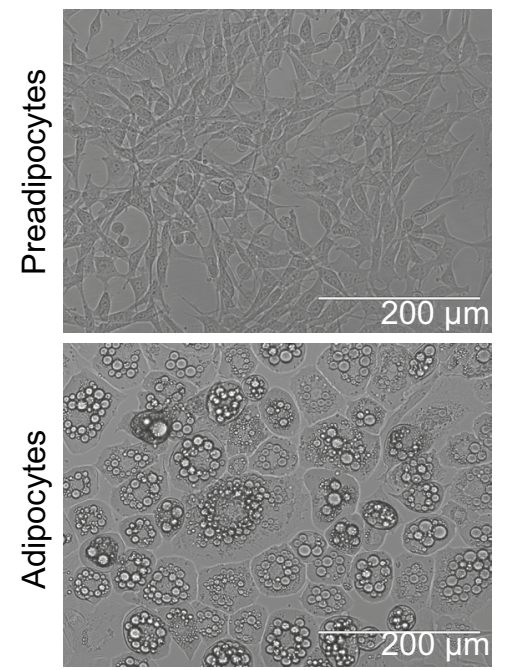

d

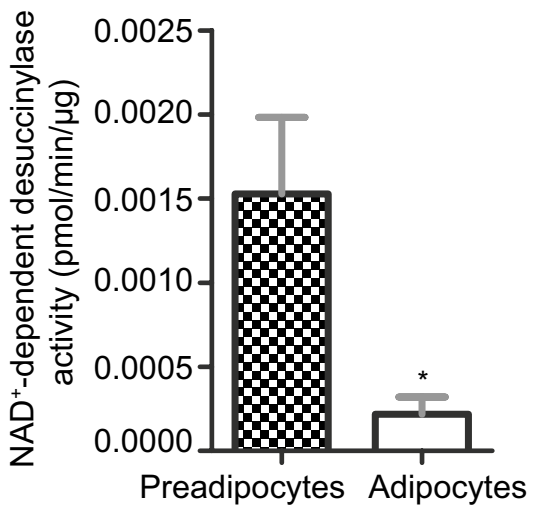

f

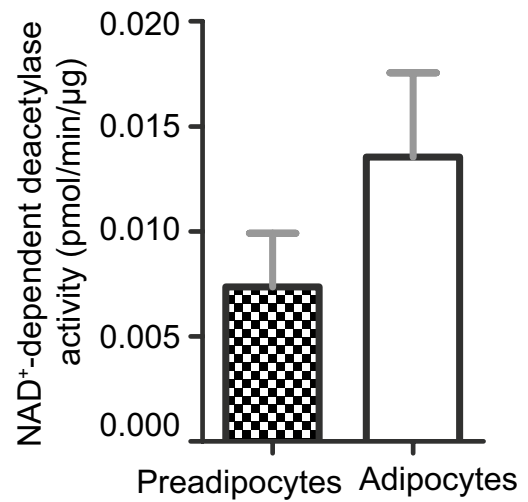

Figure 4. $\mathrm{NAD}^{+}$-dependent deacylase activities in $\mathrm{C} 2 \mathrm{C} 12$ and 3T3-L1 cell lysates. (a) Light micrograph of myoblasts (left panel), and myotubes at day 6 of differentiation (right panel); scale bar is $1000 \mu \mathrm{m}$. (b) Light micrograph of preadipocytes (left panel), and adipocytes at day 11 of differentiation (right panel); scale bar is $200 \mu \mathrm{m}$. $\mathrm{NAD}^{+}$-dependent desuccinylase activity in $150 \mu \mathrm{g}$ lysates of $(\mathbf{c})$ myoblast and myotubes and (d) $180 \mu \mathrm{g}$ lysates of preadipocytes and adipocytes. $\mathrm{NAD}^{+}$-dependent deacetylase activity in lysates $(145.6 \mu \mathrm{g})$ of (e) myoblasts and myotubes and (f) in lysates $(145.6 \mu \mathrm{g})$ of preadipocytes and adipocytes. Date represent mean \pm SEM. $\mathrm{n}=3$ for desuccinylation activity assays. Two-tailed unpaired Student's t-test was performed. ${ }^{\star} \mathrm{P}<0.05,{ }^{\star *} \mathrm{P}<0.001 . \mathrm{n}=2$ for deacetylation activity assays. 

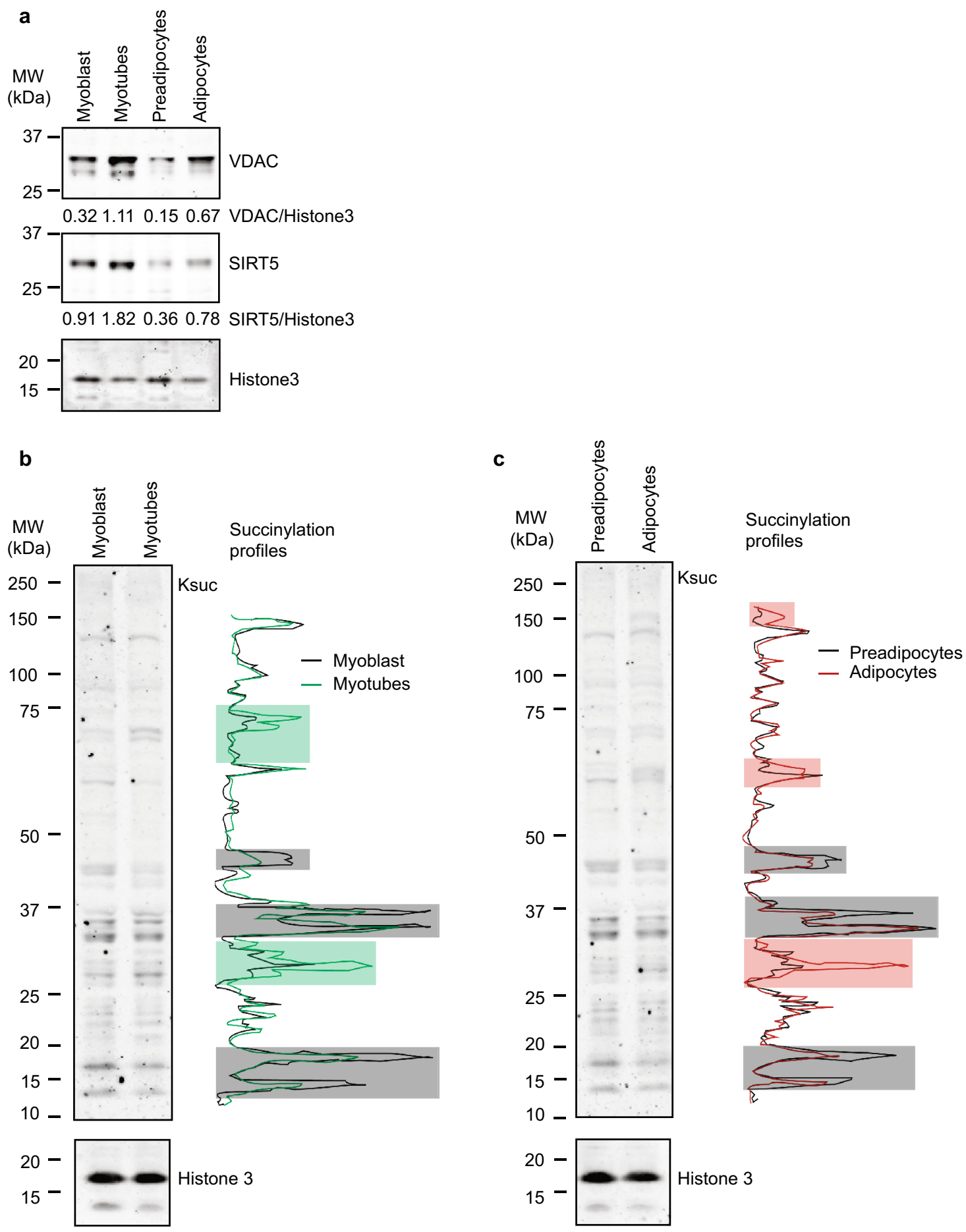

Figure 5. SIRT5 protein and succinylation levels in $\mathrm{C} 2 \mathrm{C} 12$ myoblasts and myotubes and in 3T3-L1 preadipocytes and adipocytes. (a) Western blot analysis of voltage-dependent anion channel (VDAC), SIRT5 and histone 3 . The numbers represent band intensity relative to histone 3. Blots of VDAC and SIRT5 were cropped from the same gel, and histone 3 was cropped from a different gel. Full-length blots are presented in Supplementary Fig. 3. (b) Succinyllysine levels and blot lane profiles of C2C12 myoblasts (black line) and myotubes (green line). Grey areas represent succinyllysine protein bands with higher intensity in myoblasts and green areas represent succinyllysine protein bands with lower intensity in myoblasts. (c) Succinyllysine levels and blot lane profiles of 3T3-L1 preadipocytes (black line) and adipocytes (red line). Grey areas represent succinyllysine protein bands with higher intensity in preadipocytes and red areas represent succinyllysine protein bands with lower intensity in adipocytes. In $(\mathbf{b}, \mathbf{c})$, blots of succinylation and histone 3 were grouped from different gels, and full-length blots for $(\mathbf{b}, \mathbf{c})$ are presented in Supplementary Fig. 4. 
Protein acetylation has been demonstrated to act as a regulator of cell differentiation from myoblast to myotubes $^{41}$ as well as from preadipocyte to adipocytes ${ }^{42}$. Acetylation of histones is regulated by deacetylases and acetyltransferase to maintain, activate or repress gene transcription programs $s^{43-45}$. Although succinylation has been identified on histones, and $\mathrm{NAD}^{+}$-dependent desuccinylation by SIRT7 of specific histone marks regulated DNA damage repair pathway ${ }^{25}$, it is not known whether there is a general role for succinylation and desuccinylation in regulating cell differentiation. Our findings that $\mathrm{NAD}^{+}$-dependent desuccinylase activities are higher in proliferative cells as compared to their differentiated counterparts, suggest that desuccinylation could play a role in the differentiation process. Interestingly, the $\mathrm{NAD}^{+}$-dependent desuccinylase protein, SIRT5, has been shown to support proliferative tumor cell growth in in vitro as well as in vivo models ${ }^{46-48}$. SIRT5 has also been found to be upregulated in different tumor types and its increased expression was proposed as a marker for recurrence in non-small cell lung cancer (NSCLC) ${ }^{49,50}$.

In our study, we identified a mismatch between SIRT5 protein expression level and $\mathrm{NAD}^{+}$-dependent desuccinylase activity. SIRT5 protein was expressed higher in differentiated cells as compared to proliferative cells, whereas desuccinylase activity was lower. The increased SIRT5 protein level in differentiated myotubes and adipocytes, could be explained by the fact that SIRT5 is primarily located in mitochondria ${ }^{11}$, and that increased mitochondrial biogenesis is associated with both myogenesis ${ }^{37}$ as well as adipogenesis ${ }^{39}$. In support of this, protein levels of VDAC, an abundant mitochondrial outer membrane protein, were increased in differentiated cells as compared to proliferative cells. Interestingly, that the increased protein expression of SIRT5 did not translate into a higher $\mathrm{NAD}^{+}$-dependent desuccinylase activity could implicate that mitochondria-localized SIRT5 is post-translationally modified to be inactive. Since we analysed enzymatic activity in cell lysates and added external NAD ${ }^{+}, \mathrm{NAD}^{+}$could not be a limitation for the analysed desuccinylase activity. Instead, SIRT5 could be regulated by PTMs or could be inhibited by interaction with other proteins that are part of a SIRT5 regulatory complex. Although only a limited number of SIRT5 protein interactors in the mitochondria have been identified in a large screen for mitochondrial sirtuin interactions ${ }^{51}$, it is possible that these interactors could have a role in altering the desuccinylation activity of SIRT5. For SIRT1, post-translational modifications and their impacts have been studied extensively. For example, phosphorylation on several SIRT1 sites could translocate SIRT1 and redirect it to specific targets with enhanced its enzymatic function ${ }^{52,53}$. Additionally, other PTMs have also been demonstrated to affect SIRT1 level or activity, including sumoylation ${ }^{54}$, carbonylation ${ }^{55}$, and methylation ${ }^{56}$. Another explanation for the mismatch between the SIRT5 expression and the desuccinylase activity could be that mitochondrial SIRT5 is not the main contributor to overall $\mathrm{NAD}^{+}$-dependent desuccinylase activity in myoblasts and preadipocytes. Indeed, when analysing $\mathrm{NAD}^{+}$-dependent desuccinylase activity in cell lysates of HEK293T SIRT5 KO cells, we observed substantial NAD ${ }^{+}$-dependent desuccinylase activity, whereas SIRT5 protein was not detectable. These findings highlight the importance of analysing $\mathrm{NAD}^{+}$-dependent desuccinylase activity, over only analysing expression of the protein or gene.

It has become apparent that sirtuin proteins have versatile deacylase activity ${ }^{21,24,57}$. Sirtuin members share deacylase activities among each other, but also specific deacylase, ADP-ribosyltransferase ${ }^{58,59}$ and lipoamidase ${ }^{60}$ activities have been identified for sirtuins. Deacetylation activity is shared by SIRT1 ${ }^{19}$, SIRT2 ${ }^{22}$, and SIRT3 ${ }^{20}$. Desuccinylation has been identified, apart from SIRT5 and SIRT7, for SIRT3 and SIRT4 although these sirtuins only displayed minor desuccinylation activity against a succinylated lysine peptide in vitro ${ }^{61}$.

The versatility in enzymatic activity of sirtuins is also apparent from studies on SIRT6, which has both deacetylase activity as well as de-fatty acylase activity and ADP-ribosyltransferase activity ${ }^{59,62,63}$. Specific mutations of SIRT6 identified in tumors could even predispose for one activity over the other ${ }^{64}$. In our cell lines and physiological conditions tested, the $\mathrm{NAD}^{+}$-dependent desuccinylase activities of cell lysates were approximately tenfold lower than the $\mathrm{NAD}^{+}$-dependent deacetylase activities. Interestingly, the deacetylase activity did not change upon differentiation, whereas desuccinylase activity was different. Interestingly, in our study, we even identified two distinct desuccinylation reaction rates in cell lysates, one initial high activity and a second slower one. This could possibly be explained by differential substrate-binding affinity by multiple desuccinylases. Further studies are needed to explore the desuccinylation potential of specific proteins.

Overall, we optimized a fluorescence-based assay for detecting cellular NAD ${ }^{+}$-dependent desuccinylase activity, and demonstrated that $\mathrm{NAD}^{+}$-dependent desuccinylase activity is lowered in differentiated myotubes and adipocytes. The observed mismatch between SIRT5 protein expression level and $\mathrm{NAD}^{+}$-dependent desuccinylase activity highlights the relevance of analysing sirtuin enzymatic activities in physiological contexts. The high desuccinylase activity in proliferating cells is of relevance to analyse how desuccinylase activity contributes to tumor cell function and how sirtuins with $\mathrm{NAD}^{+}$-dependent desuccinylase activity are regulated during proliferation and differentiation.

\section{Material and methods}

His-SIRT5 expression and purification. The human His-SIRT5 $(6 \times$ His $)$ plasmid was a gift from Cheryl Arrowsmith (Addgene plasmid \# 25487). Human SIRT5 gene is inserted into the vector pET28a-LIC, and six histidine residues are fused into the SIRT5 protein on $\mathrm{N}$ terminal, and the plasmid is resistant to kanamycin. The plasmid was transformed into chemical competent E. coli BL21 by heat shock as previously published ${ }^{65}$, with minor modifications. Briefly, $1 \mu \mathrm{g}$ of plasmid DNA was added to $50 \mu \mathrm{l}$ competent $E$. coli BL21 cells, incubated for $30 \mathrm{~min}$ on ice, heat-shocked for $11 \mathrm{~s}$ at $42^{\circ} \mathrm{C}$ and returned to ice for $5 \mathrm{~min}$. After the cells were incubated in $950 \mu \mathrm{l}$ Lysogeny broth (LB) medium for $1 \mathrm{~h}$ at $37^{\circ} \mathrm{C}$. $100 \mu \mathrm{l}$ of the transformation mix was plated on LB agar plates containing $50 \mu \mathrm{g} / \mathrm{ml}$ kanamycin and incubated overnight at $37^{\circ} \mathrm{C}$. For His-SIRT5 protein expression level, a single colony was inoculated in $3 \mathrm{ml} \mathrm{LB}$ medium with $50 \mu \mathrm{g} / \mathrm{ml}$ kanamycin, incubated for $8 \mathrm{~h}$ at $37^{\circ} \mathrm{C}$ with shaking at $220 \mathrm{rpm}$ using an incubator shaker (G25, New Brunswick Scientific), and the bacterial starter culture was stored at $4{ }^{\circ} \mathrm{C}$. Next day, $100 \mu \mathrm{l}$ of bacterial starter culture was inoculated to $100 \mathrm{ml} \mathrm{LB}$ medium 
with $50 \mu \mathrm{g} / \mathrm{ml}$ kanamycin in a $300 \mathrm{ml}$ Erlenmeyer flask, incubated at $37^{\circ} \mathrm{C}$ with shaking at $220 \mathrm{rpm}$ until an $\mathrm{OD}_{600}$ of 0.25 , after which the cultures were placed at $22^{\circ} \mathrm{C}$ and Isopropyl $\beta$-D-1-thiogalactopyranoside (IPTG) was added to a final concentration of $1 \mathrm{mM}$. Cells were harvested $18 \mathrm{~h}$ after IPTG induction by centrifugation at $6000 \times \mathrm{g}$ for $15 \mathrm{~min}$ at $4{ }^{\circ} \mathrm{C}$. For purification of His-SIRT5, 3-4 mg of E.coli pellet was resuspended in $3 \mathrm{ml}$ lysis buffer $(10 \mathrm{mM}$ Tris/ $\mathrm{HCl} \mathrm{pH} \mathrm{8.0,500} \mathrm{mM} \mathrm{NaCl}$, and $1 \mathrm{mg} / \mathrm{ml}$ lysozyme) and incubated end-over-end for $30 \mathrm{~min}$ at $4{ }^{\circ} \mathrm{C}$. Cells were then sonicated at $40 \%$ amplitude (burst of $1 \mathrm{~s}$ followed by $3 \mathrm{~s}$ interval) for $5 \mathrm{~min}$ on ice using a digital sonifier (Branson SLPe). Insoluble debris in the cell lysate was removed by centrifugation at $8500 \times g$ and $4{ }^{\circ} \mathrm{C}$ for $15 \mathrm{~min}$. Imidazole $/ \mathrm{HCl}$ at $\mathrm{pH} 8.0$ was added to the supernatant to a final concentration of $30 \mathrm{mM}$. Crude His-SIRT5 was purified using HisLink protein purification resin (\#V8823, Promega) in combination with a chromatography column (\#731-1150, Bio-Rad). The protein purification resin consists of microporous silica resin which contains a high level of tetradentate-chelated nickel and can purify polyhistidine-tagged recombinant proteins efficiently. To purify crude His-SIRT5, $0.4 \mathrm{ml}$ of the HisLink protein purification resin was loaded to a chromatography column, then the resin was first equilibrated by washing five times with washing buffer (25 mM Tris/ $\mathrm{HCl} \mathrm{pH} \mathrm{8.0,500} \mathrm{mM} \mathrm{NaCl,} \mathrm{and} 30 \mathrm{mM}$ imidazole). E. coli lysate was then loaded onto the equilibrated column and was allowed to pass through, and this step was repeated once. Then, the column was washed five times with the washing buffer, and His-SIRT5 was eluted with $200 \mu$ l of elution buffer ( $25 \mathrm{mM}$ Tris/ $\mathrm{HCl} \mathrm{pH} \mathrm{8.0,100} \mathrm{mM} \mathrm{NaCl,} \mathrm{and} 500 \mathrm{mM}$ imidazole). Elution fractions were checked for SIRT5 content using gel electrophoresis and Coomassie staining (Supplementary Fig. 1). Prior to use in further experiments, imidazole was removed from the eluted His-SIRT5 using ultra-0.5 centrifugal filter units (\#UFC501096, Merck Millipore) according to the manufacturer's instruction. Briefly, $50 \mu \mathrm{l}$ of eluted His-SIRT5 was loaded to a filter column, and $450 \mu \mathrm{l}$ of exchange buffer $(25 \mathrm{mM}$ Tris/ $\mathrm{HCl} \mathrm{pH} 8.0$ and $100 \mathrm{mM} \mathrm{NaCl})$ was added, followed by centrifugation at $14,000 \times g$ for $15 \mathrm{~min}$ at $4{ }^{\circ} \mathrm{C}$. The flow through was discarded and another $450 \mu \mathrm{l}$ of exchange buffer was added to the column and the same centrifugation step was repeated once. Then the His-SIRT5 was collected by reverse centrifugation in an Eppendorf tube at $1000 \times g$ for $2 \mathrm{~min}$ at $4^{\circ} \mathrm{C}$. The protein concentration of His-SIRT5 was determined using a Bradford protein assay (\#23200, Thermo Scientific), after which the His-SIRT5 was preserved in $1 \times$ freezing buffer $(50 \mathrm{mM}$ Tris/ $\mathrm{HCl} \mathrm{pH} \mathrm{8.0,500} \mathrm{mM} \mathrm{NaCl}, 500 \mathrm{mM} \mathrm{DTT}$, and $20 \%$ glycerol $)$ and aliquoted with $10 \mu \mathrm{l} /$ tube and the aliquots were stored at $-80^{\circ} \mathrm{C}$ until use.

Cell culture. Murine 3T3-L1 preadipocytes (ATCC, \#CL-173) were cultured at $37^{\circ} \mathrm{C}, 5 \% \mathrm{CO}_{2}$ in $3 \mathrm{~T} 3-\mathrm{L} 1$ medium, which consisted of DMEM (\#11880-028, Gibco) supplemented with $10 \%(\mathrm{v} / \mathrm{v})$ foetal bovine serum (FBS, \#06Q3501K, Gibco), 4.5 g/l glucose (\#G7021, Sigma-Aldrich), 4 mM L-glutamine (\#25030-024, Gibco) and an antibiotic-antimycotic mix (10,000 units/ml of penicillin, 10,000 $\mu \mathrm{g} / \mathrm{ml}$ of streptomycin, and $25 \mu \mathrm{g} / \mathrm{ml}$ Amphotericin B, \#15240-062, Gibco). For differentiation of preadipocytes into adipocytes, 3T3-L1 preadipocytes $(8,000$ cells/well) were first seeded in 6-well plates in 3T3-L1 medium, and differentiation was started $48 \mathrm{~h}$ after the preadipocytes reached $100 \%$ confluency by switching to $3 \mathrm{~T} 3-\mathrm{L} 1$ differentiation medium ( $2 \mathrm{ml} /$ well) in the same culture plates. The 3T3-L1 differentiation medium consisted of 3T3-L1 medium supplemented with a final concentration of $1 \mu \mathrm{M}$ insulin (\#I0516, Sigma-Aldrich), $0.5 \mathrm{mM}$ 3-isobutyl-1-methylxanthine (\#5879, Sigma-Aldrich), $1 \mu \mathrm{M}$ dexamethasone (\#D4902, Sigma-Aldrich) and $1 \mu \mathrm{M} 15$-Deoxy- $\Delta 12$, 14 -prostaglandin J2 (\#D8440, Sigma-Aldrich). The cells were cultured in the differentiation medium for $48 \mathrm{~h}$, then in differentiation maintaining medium (3T3-L1 medium containing $1 \mu \mathrm{M}$ insulin) until the cells were harvested at day 11 of differentiation.

Murine C2C12 myoblasts (ATCC, \#CRL-1772) were cultured in C2C12 growth medium, consisted of DMEM (\#11960-044, Gibco) supplemented with 25 mM HEPES (\#15630080, Thermo Scientific), 10\% FBS, and antibiotic-antimycotic mix. For differentiation of myoblasts into myotubes, myoblasts $\left(3 \times 10^{5}\right.$ cells/well) were first seeded in a 6-well plate in the $\mathrm{C} 2 \mathrm{C} 12$ growth medium, and differentiation of myoblasts was started when the myoblasts reached $90 \%$ confluency by switching to C2C12 differentiation medium that contained $2 \%$ horse serum (\#26050070, Gibco) instead of 10\% FBS. Cells were cultured in the C2C12 differentiation medium until harvest at day 6 of differentiation.

Generation of SIRT5 knockout HEK293T cells. SIRT5 knockout HEK293T cells were generated using the CRISPR-Cas9 system following the directions outline in Ran et al. ${ }^{66}$. Briefly, sgRNA against SIRT5 oligos (sequence: GGCTGCTGGGTACACCACAG) were resuspended in water, annealed, then phosphorylated using T4 polynucleotide kinase. Then, the ligated oligos and PX459 vector were digested and ligated together using BbsI and the T7 ligase, respectively. HEK293T cells (ATCC, \#CRL-11268), cultured following ATCC guidelines, were transfected with the PX459-sgRNA vector using Lipofectamine 3000 according to manufacturer's instructions. Transfected cells were selected using puromycin $(3 \mu \mathrm{g} / \mathrm{ml})$ for $48 \mathrm{~h}$. To achieve single-cell colonies, cells remaining after selection were diluted to a density of 50 cells $/ 10 \mathrm{ml}$ of media, and $100 \mu \mathrm{l}$ of the diluted cell suspension per well was plated to 96-well plates. SIRT5 status in the colonies were assessed using immunoblotting. Colonies lacking SIRT5 protein were then sequenced to confirm Cas9-mediated genomic alterations at the location targeted by the sgRNA. Colonies with SIRT5 levels comparable to WT HEK293T cells were used as controls for SIRT5 KO cells.

Desuccinylation activity assays. Desuccinylation activity was measured using a fluorogenic reporter assay. Succinylated-substrate (\#BML-KI590), assay buffer (\#BML-KI286-0020), developer concentrate (20x, \#BML-KI105), NAD (\#BML-KI282), and NAM (\#BML-KI283-0500) were all purchased from Enzo. Assay reagents were prepared freshly in the assay buffer prior to the assay and were kept on ice until use.

For desuccinylase activity in cells, trypsinized, washed and pelleted cells were resuspended in lysis buffer $(50 \mathrm{mM}$ Tris/ $\mathrm{HCl}, \mathrm{pH} 8.0,137 \mathrm{mM} \mathrm{NaCl}, 2.7 \mathrm{mM} \mathrm{KCl}, 1 \mathrm{mM} \mathrm{MgCl} 2,0.1 \%$ Triton X-100, and protease inhibitor 
(\#04693159001, Roche)) and sonicated on ice at 40\% amplitude (burst of $1 \mathrm{~s}$ followed by $3 \mathrm{~s}$ cooling) for 12 bursts using a Branson SLPe digital sonifier. Cell lysates were centrifuged at $10,000 \times g, 4{ }^{\circ} \mathrm{C}$ for $10 \mathrm{~min}$, and the supernatants were used in further experiments. Samples were equalized with lysis buffer on protein concentration after determination using DC protein assays (\#5000116, Bio-Rad). Protein input for each sample in the desuccinylase reaction was indicated in the figure legends. Prior to use in desuccinylation reaction, $28 \mu$ of cell lysates were incubated at a $37^{\circ} \mathrm{C}$ water bath with shaking at $60 \mathrm{rpm}$ (Shaking water bath, VWR) in $1.5 \mathrm{ml}$ Eppendorf tubes for $10 \mathrm{~min}$ to degrade endogenous $\mathrm{NAD}^{+}$, then $0.6 \mu \mathrm{l}$ of $50 \mathrm{mM}$ dithiothreitol ${ }^{67}$ dissolved in assay buffer was added to all cell lysates, and incubation continued for an additional $5 \mathrm{~min}$. The catalytic reactions were performed at $37^{\circ} \mathrm{C}$ with shaking at $60 \mathrm{rpm}$, initiated by adding $28 \mu \mathrm{l}$ of pre-warmed $\left(37^{\circ} \mathrm{C}\right) 20 \mu \mathrm{M}$ succinylsubstrate (final concentration of $10 \mu \mathrm{M}$ ) in combination with either $1 \mathrm{mM} \mathrm{NAD}^{+}$(final concentration of $500 \mu \mathrm{M}$ ) or assay buffer only (negative control). After adding the substrates, the tubes were vortexed at $2200 \mathrm{rpm}$ for $2 \mathrm{~s}$ with a Minishaker (IKA MS2) and then placed at the $37^{\circ} \mathrm{C}$ water bath. The reactions were stopped after $10 \mathrm{~min}$, unless stated otherwise, by adding $56 \mu$ of $1 \times$ developer containing $2 \mathrm{mM}$ NAM, vortexing at $2200 \mathrm{rpm}$ for $2 \mathrm{~s}$, then incubating at $25^{\circ} \mathrm{C}$ for $15 \mathrm{~min}$. Finally, $100 \mu \mathrm{l}$ of each sample was loaded onto half-area black 96 -well plates (\#3686, Corning) and the fluorescence was read with excitation at $360 \mathrm{~nm}$ and emission at $460 \mathrm{~nm}$ at $25^{\circ} \mathrm{C}$ on a Biotek Synergy HT microplate reader. Fluorescence signal of the negative control group was subtracted from each experimental sample. To analyse the desuccinylation activity of His-SIRT5, the same procedure was followed as for cell lysate, but instead of cell lysates, purified recombinant His-SIRT5 was used. The amount of His-SIRT5 used in each assay was indicated in figure legends.

NAM sensitivity of desuccinylation activity. For analysing NAM sensitivity of cellular desuccinylation activity, the assay procedure was the same as desuccinylation assay described above, with a slightly different reaction system composition, as follows: $14 \mu \mathrm{l}$ cell lysate $(187.3 \mu \mathrm{g}), 28 \mu \mathrm{l}$ of $20 \mu \mathrm{M}$ succinylated-substrate containing $1 \mathrm{mM} \mathrm{NAD}^{+}$, and $14 \mu \mathrm{l} \mathrm{NAM}(0.04-4000 \mu \mathrm{M}$, resulting in a final concentration in the reaction system of $0.01-$ $1000 \mu \mathrm{M}$ ). The reaction was stopped with either $56 \mu \mathrm{l} 1 \times$ developer (experimental samples) or $56 \mu \mathrm{l} 1 \times$ developer containing $2 \mathrm{mM}$ NAM (negative control sample). The fluorescence signal was subtracted from signal in the negative control group, which consisted of $14 \mu \mathrm{l}$ cell lysate, $28 \mu \mathrm{l}$ succinylated-substrate without $\mathrm{NAD}^{+}$and $14 \mu \mathrm{l}$ assay buffer. The same procedure was used to analyse NAM sensitivity of His-SIRT5 desuccinylation activity, except that His-SIRT5 $(0.06 \mu \mathrm{g})$ was used instead of cell lysate.

Deacetylation activity assay. Deacetylation activities of cell lysates and recombinant His-SIRT5 were determined similarly to the desuccinylation activity, except that an acetylated-fluorogenic substrate (\#BMLKI179, Enzo) rather than a succinylated-substrate was used and $1 \times$ developer II (\#BML-KI176-1250, Enzo) was used to stop the deacetylation reaction.

Western blotting. Cells were lysed in lysis buffer $(50 \mathrm{mM}$ Tris/HCl pH 7.4) containing deacylase inhibitors ( $1 \mu \mathrm{M}$ trichostatin A and $10 \mathrm{mM}$ NAM) as well as protease inhibitor cocktail (\#04693159001, Roche) by sonication on ice, the cell lysate sonication procedure was the same as described in the Desuccinylation activity assays section. Samples were equalized to the same protein level with the lysis buffer following quantification by DC protein assays. Cell lysates ( $30 \mu \mathrm{g}$ protein) were separated on NuPAGE $4-12 \%$ gradient gels (\#NP0322, Thermo Scientific) at $110 \mathrm{~V}$ for $35 \mathrm{~min}$, followed by $150 \mathrm{~V}$ for $40 \mathrm{~min}$ at room temperature. After which, proteins on the gel were immediately transferred to a nitrocellulose membrane at $300 \mathrm{~mA}$ for $1 \mathrm{~h}$ on ice. Antibodies against SIRT5 (\#8782, Cell Signaling Technology), succinyllysine (\#401, PTM Biolabs), voltage-dependent anion channel (VDAC) (\#ab14734, Abcam) and Histone 3 (\#9715, Cell Signaling Technology) were used to identify the respective targets. IRDye Donkey anti-rabbit (\#926-32213, LI-COR Biosciences) and Goat anti-mouse (\#92632210, LI-COR Biosciences) were used and signals were detected using an Odyssey scanner (LI-COR). Lane profile analyses was performed using Image J $1.51 \mathrm{p}$.

Statistics. Statistical analysis was performed using GraphPad Prism 5.04. Data was compared using the twotailed unpaired Student's t-test. Data represent mean \pm SEM. P values below 0.05 were considered significant.

\section{Data availability}

All data generated or analysed during this study are included in this published article (and its "Supplementary Information" files).

Received: 8 May 2019; Accepted: 3 September 2020

Published online: 12 October 2020

\section{References}

1. Zhang, Z. et al. Identification of lysine succinylation as a new post-translational modification. Nat. Chem. Biol. 7, 58-63. https:// doi.org/10.1038/nchembio.495 (2011).

2. Walsh, C. T., Garneau-Tsodikova, S. \& Gatto, G. J. Jr. Protein posttranslational modifications: The chemistry of proteome diversifications. Angew. Chem. Int. Ed. Engl. 44, 7342-7372. https://doi.org/10.1002/anie.200501023 (2005).

3. Eshun-Wilson, L. et al. Effects of a-tubulin acetylation on microtubule structure and stability. Proc. Natl. Acad. Sci. USA 116, 10366-10371. https://doi.org/10.1073/pnas.1900441116 (2019).

4. Pougovkina, O. et al. Mitochondrial protein acetylation is driven by acetyl-CoA from fatty acid oxidation. Hum. Mol. Genet. 23, 3513-3522. https://doi.org/10.1093/hmg/ddu059 (2014).

5. Li, F. et al. NADP(+)-IDH mutations promote hypersuccinylation that impairs mitochondria respiration and induces apoptosis resistance. Mol. Cell 60, 661-675. https://doi.org/10.1016/j.molcel.2015.10.017 (2015). 
6. Wagner, G. R. \& Payne, R. M. Widespread and enzyme-independent Nepsilon-acetylation and Nepsilon-succinylation of proteins in the chemical conditions of the mitochondrial matrix. J. Biol. Chem. 288, 29036-29045. https://doi.org/10.1074/jbc.M113.48675 3 (2013).

7. Lin, H. \& Caroll, K. S. Introduction: Posttranslational protein modification. Chem. Rev. 118, 887-888. https://doi.org/10.1021/acs. chemrev.7b00756 (2018).

8. Weinert, B. T. et al. Lysine succinylation is a frequently occurring modification in prokaryotes and eukaryotes and extensively overlaps with acetylation. Cell Rep. 4, 842-851. https://doi.org/10.1016/j.celrep.2013.07.024 (2013).

9. Xie, Z. et al. Lysine succinylation and lysine malonylation in histones. Mol. Cell. Proteomics 11, 100-107. https://doi.org/10.1074/ mcp.M111.015875 (2012).

10. Smestad, J., Erber, L., Chen, Y. \& Maher, L. J. Chromatin succinylation correlates with active gene expression and is perturbed by defective TCA cycle metabolism. iScience 2, 63-75. https://doi.org/10.1016/j.isci.2018.03.012 (2018).

11. Park, J. et al. SIRT5-mediated lysine desuccinylation impacts diverse metabolic pathways. Mol. Cell 50, 919-930. https://doi. org/10.1016/j.molcel.2013.06.001 (2013).

12. Rardin, M. J. et al. SIRT5 regulates the mitochondrial lysine succinylome and metabolic networks. Cell Metab. 18, 920-933. https ://doi.org/10.1016/j.cmet.2013.11.013 (2013).

13. Sadhukhan, S. et al. Metabolomics-assisted proteomics identifies succinylation and SIRT5 as important regulators of cardiac function. Proc. Natl. Acad. Sci. USA 113, 4320-4325. https://doi.org/10.1073/pnas.1519858113 (2016).

14. Hershberger, K. A. et al. Sirtuin 5 is required for mouse survival in response to cardiac pressure overload. J. Biol. Chem. 292, 19767-19781. https://doi.org/10.1074/jbc.M117.809897 (2017).

15. Chen, H. et al. Mild metabolic perturbations alter succinylation of mitochondrial proteins. J. Neurosci. Res. https://doi.org/10.1002/ jnr.24103 (2017).

16. Gibson, G. E. et al. Alpha-ketoglutarate dehydrogenase complex-dependent succinylation of proteins in neurons and neuronal cell lines. J. Neurochem. 134, 86-96. https://doi.org/10.1111/jnc.13096 (2015).

17. Meyer, J. G. et al. Temporal dynamics of liver mitochondrial protein acetylation and succinylation and metabolites due to high fat diet and/or excess glucose or fructose. PLoS ONE 13, e0208973. https://doi.org/10.1371/journal.pone.0208973 (2018).

18. Bentley, N. L. et al. Protein hypoacylation induced by Sirt5 overexpression has minimal metabolic effect in mice. Biochem. Biophys. Res. Commun. 503, 1349-1355. https://doi.org/10.1016/j.bbrc.2018.07.047 (2018).

19. Vaziri, H. et al. hSIR2(SIRT1) functions as an NAD-dependent p53 deacetylase. Cell 107, 149-159. https://doi.org/10.1016/s0092 -8674(01)00527-x (2001).

20. Onyango, P., Celic, I., McCaffery, J. M., Boeke, J. D. \& Feinberg, A. P. SIRT3, a human SIR2 homologue, is an NAD-dependent deacetylase localized to mitochondria. Proc. Natl. Acad. Sci. USA 99, 13653-13658. https://doi.org/10.1073/pnas.222538099 (2002).

21. Anderson, K. A. et al. SIRT4 is a lysine deacylase that controls leucine metabolism and insulin secretion. Cell Metab. 25, 838-855. e815. https://doi.org/10.1016/j.cmet.2017.03.003 (2017).

22. North, B. J., Marshall, B. L., Borra, M. T., Denu, J. M. \& Verdin, E. The human Sir2 ortholog, SIRT2, is an NAD+-dependent tubulin deacetylase. Mol. Cell 11, 437-444 (2003).

23. Houtkooper, R. H., Pirinen, E. \& Auwerx, J. Sirtuins as regulators of metabolism and healthspan. Nat. Rev. Mol. Cell Biol. 13, 225-238. https://doi.org/10.1038/nrm3293 (2012).

24. Du, J. et al. Sirt5 is a NAD-dependent protein lysine demalonylase and desuccinylase. Science 334, 806-809. https://doi.org/10.1126/ science.1207861 (2011).

25. Li, L. et al. SIRT7 is a histone desuccinylase that functionally links to chromatin compaction and genome stability. Nat. Commun. 7, 12235. https://doi.org/10.1038/ncomms12235 (2016).

26. Tan, M. et al. Lysine Glutarylation is a protein posttranslational modification regulated by SIRT5. Cell Metab. 19, 605-617. https ://doi.org/10.1016/j.cmet.2014.03.014 (2014).

27. Nakagawa, T., Lomb, D. J., Haigis, M. C. \& Guarente, L. SIRT5 deacetylates carbamoyl phosphate synthetase 1 and regulates the urea cycle. Cell 137, 560-570. https://doi.org/10.1016/j.cell.2009.02.026 (2009).

28. Ryu, D. et al. A SIRT7-dependent acetylation switch of GABPbeta1 controls mitochondrial function. Cell Metab. 20, 856-869. https://doi.org/10.1016/j.cmet.2014.08.001 (2014).

29. Yu, J. et al. Regulation of serine-threonine kinase Akt activation by NAD(+)-dependent deacetylase SIRT7. Cell Rep. 18, 1229-1240. https://doi.org/10.1016/j.celrep.2017.01.009 (2017).

30. Wagner, G. R. et al. A class of reactive Acyl-CoA Species reveals the non-enzymatic origins of protein acylation. Cell Metab. 25, 823. https://doi.org/10.1016/j.cmet.2017.03.006 (2017).

31. Houtkooper, R. H., Canto, C., Wanders, R. J. \& Auwerx, J. The secret life of NAD+: An old metabolite controlling new metabolic signaling pathways. Endocr. Rev. 31, 194-223. https://doi.org/10.1210/er.2009-0026 (2010).

32. Schuster, S. et al. A continuous sirtuin activity assay without any coupling to enzymatic or chemical reactions. Sci. Rep. 6, 22643. https://doi.org/10.1038/srep22643 (2016).

33. Madsen, A. S. \& Olsen, C. A. Substrates for efficient fluorometric screening employing the NAD-dependent sirtuin 5 lysine deacylase (KDAC) enzyme. J. Med. Chem. 55, 5582-5590. https://doi.org/10.1021/jm300526r (2012).

34. Maurer, B. et al. Inhibitors of the NAD(+)-Dependent protein desuccinylase and demalonylase Sirt5. ACS Med. Chem. Lett. 3, 1050-1053. https://doi.org/10.1021/ml3002709 (2012).

35. Pacella-Ince, L., Zander-Fox, D. L. \& Lane, M. Mitochondrial SIRT5 is present in follicular cells and is altered by reduced ovarian reserve and advanced maternal age. Reprod. Fertil. Dev. 26, 1072-1083. https://doi.org/10.1071/RD13178 (2014).

36. Polletta, L. et al. SIRT5 regulation of ammonia-induced autophagy and mitophagy. Autophagy 11, 253-270. https://doi. org/10.1080/15548627.2015.1009778 (2015).

37. Remels, A. H. et al. Regulation of mitochondrial biogenesis during myogenesis. Mol. Cell. Endocrinol. 315, 113-120. https://doi. org/10.1016/j.mce.2009.09.029 (2010).

38. Kraft, C. S. et al. Control of mitochondrial biogenesis during myogenesis. Am. J. Physiol. Cell Physiol. 290, C1119-1127. https:// doi.org/10.1152/ajpcell.00463.2005 (2006).

39. Wilson-Fritch, L. et al. Mitochondrial biogenesis and remodeling during adipogenesis and in response to the insulin sensitizer rosiglitazone. Mol. Cell. Biol. 23, 1085-1094 (2003).

40. Tormos, K. V. et al. Mitochondrial complex III ROS regulate adipocyte differentiation. Cell Metab. 14, 537-544. https://doi. org/10.1016/j.cmet.2011.08.007 (2011)

41. Mal, A. \& Harter, M. L. MyoD is functionally linked to the silencing of a muscle-specific regulatory gene prior to skeletal myogenesis. Proc. Natl. Acad. Sci. USA 100, 1735-1739. https://doi.org/10.1073/pnas.0437843100 (2003).

42. Yoo, E. J., Chung, J. J., Choe, S. S., Kim, K. H. \& Kim, J. B. Down-regulation of histone deacetylases stimulates adipocyte differentiation. J. Biol. Chem. 281, 6608-6615. https://doi.org/10.1074/jbc.M508982200 (2006).

43. Verdone, L., Agricola, E., Caserta, M. \& Di Mauro, E. Histone acetylation in gene regulation. Brief Funct. Genomic Proteomic 5, 209-221. https://doi.org/10.1093/bfgp/ello28 (2006).

44. Mehrotra, S. et al. Histone hypoacetylation-activated genes are repressed by acetyl-CoA- and chromatin-mediated mechanism. Biochim. Biophys. Acta 751-763, 2014. https://doi.org/10.1016/j.bbagrm.2014.05.029 (1839).

45. Brownell, J. E. et al. Tetrahymena histone acetyltransferase A: A homolog to yeast Gcn5p linking histone acetylation to gene activation. Cell 84, 843-851. https://doi.org/10.1016/s0092-8674(00)81063-6 (1996) 
46. Du, Z. et al. Targeting a Sirt5-positive subpopulation overcomes multidrug resistance in wild-type Kras colorectal carcinomas. Cell Rep. 22, 2677-2689. https://doi.org/10.1016/j.celrep.2018.02.037 (2018).

47. Yang, X. et al. SHMT2 Desuccinylation by SIRT5 drives cancer cell proliferation. Cancer Res. 78, 372-386. https://doi. org/10.1158/0008-5472.can-17-1912 (2018).

48. Lv, X. B. et al. SUN2 exerts tumor suppressor functions by suppressing the Warburg effect in lung cancer. Sci. Rep. 5, 17940. https ://doi.org/10.1038/srep17940 (2015).

49. Lu, W. D., Zuo, Y., Feng, Y. F. \& Zhang, M. SIRT5 facilitates cancer cell growth and drug resistance in non-small cell lung cancer. Tumor Biol. 35, 10699-10705. https://doi.org/10.1007/s13277-014-2372-4 (2014).

50. Kumar, S. \& Lombard, D. B. Functions of the sirtuin deacylase SIRT5 in normal physiology and pathobiology. Crit. Rev. Biochem. Mol. Biol. 53, 311-334. https://doi.org/10.1080/10409238.2018.1458071 (2018).

51. Yang, W. et al. Mitochondrial sirtuin network reveals dynamic SIRT3-dependent deacetylation in response to membrane depolarization. Cell 167, 985-1000.e1021. https://doi.org/10.1016/j.cell.2016.10.016 (2016).

52. Nasrin, N. et al. JNK1 phosphorylates SIRT1 and promotes its enzymatic activity. PLoS ONE 4, e8414. https://doi.org/10.1371/ journal.pone.0008414 (2009).

53. Sasaki, T. et al. Phosphorylation regulates SIRT1 function. PLoS ONE 3, e4020. https://doi.org/10.1371/journal.pone.0004020 (2008).

54. Yang, Y. et al. SIRT1 sumoylation regulates its deacetylase activity and cellular response to genotoxic stress. Nat. Cell Biol. 9, 1253-1262. https://doi.org/10.1038/ncb1645 (2007).

55. Caito, S. et al. SIRT1 is a redox-sensitive deacetylase that is post-translationally modified by oxidants and carbonyl stress. FASEB J. 24, 3145-3159. https://doi.org/10.1096/fj.09-151308 (2010).

56. Liu, X. et al. Methyltransferase Set7/9 regulates p53 activity by interacting with Sirtuin 1 (SIRT1). Proc. Natl. Acad. Sci. USA 108, 1925-1930. https://doi.org/10.1073/pnas.1019619108 (2011).

57. Kumar, S. \& Lombard, D. B. Mitochondrial sirtuins and their relationships with metabolic disease and cancer. Antioxid. Redox Signal. 22, 1060-1077. https://doi.org/10.1089/ars.2014.6213 (2015).

58. Haigis, M. C. et al. SIRT4 inhibits glutamate dehydrogenase and opposes the effects of calorie restriction in pancreatic beta cells. Cell 126, 941-954. https://doi.org/10.1016/j.cell.2006.06.057 (2006).

59. Liszt, G., Ford, E., Kurtev, M. \& Guarente, L. Mouse Sir2 homolog SIRT6 is a nuclear ADP-ribosyltransferase. J. Biol. Chem. 280, 21313-21320. https://doi.org/10.1074/jbc.M413296200 (2005).

60. Mathias, R. A. et al. Sirtuin 4 is a lipoamidase regulating pyruvate dehydrogenase complex activity. Cell 159, 1615-1625. https:// doi.org/10.1016/j.cell.2014.11.046 (2014).

61. Feldman, J. L., Baeza, J. \& Denu, J. M. Activation of the protein deacetylase SIRT6 by long-chain fatty acids and widespread deacylation by mammalian sirtuins. J. Biol. Chem. 288, 31350-31356. https://doi.org/10.1074/jbc.C113.511261 (2013).

62. Michishita, E. et al. SIRT6 is a histone H3 lysine 9 deacetylase that modulates telomeric chromatin. Nature 452, 492-496. https:// doi.org/10.1038/nature06736 (2008).

63. Jiang, H. et al. SIRT6 regulates TNF-alpha secretion through hydrolysis of long-chain fatty acyl lysine. Nature 496, 110-113. https ://doi.org/10.1038/nature12038 (2013)

64. Kugel, S. et al. Identification of and molecular basis for SIRT6 loss-of-function point mutations in cancer. Cell Rep. 13, 479-488. https://doi.org/10.1016/j.celrep.2015.09.022 (2015).

65. Kumar, S. \& Lombard, D. B. Generation and purification of catalytically active recombinant Sirtuin5 (SIRT5) protein. Methods Mol. Biol. 1436, 241-257. https://doi.org/10.1007/978-1-4939-3667-0_16 (2016).

66. Ran, F. A. et al. Genome engineering using the CRISPR-Cas9 system. Nat. Protoc. 8, 2281-2308. https://doi.org/10.1038/nprot .2013 .143 (2013).

67. Hu, J., He, B., Bhargava, S. \& Lin, H. A fluorogenic assay for screening Sirt6 modulators. Org. Biomol. Chem. 11, 5213-5216. https ://doi.org/10.1039/c3ob41138a (2013).

\section{Acknowledgements}

TY has received financial support from the China Scholarship Council (Grant no. 201606350170). AG was supported by T32 AG000114. Generation of the SIRT5 KO cells in the Lombard lab was supported by R01GM101171. His-SIRT5 plasmid was a gift from Cheryl Arrowsmith (Addgene plasmid \# 25487).

\section{Author contributions}

T.Y. performed all experiments, analysed all data, drafted and wrote the manuscript. A.G. and D.L. generated and provided essential experimental resources. J.K. and V.B. supervised study, discussed data and edited manuscript. All authors commented on the manuscript.

\section{Competing interests}

The authors declare no competing interests.

\section{Additional information}

Supplementary information is available for this paper at https://doi.org/10.1038/s41598-020-72833-7.

Correspondence and requests for materials should be addressed to V.C.J.d.B.

Reprints and permissions information is available at www.nature.com/reprints.

Publisher's note Springer Nature remains neutral with regard to jurisdictional claims in published maps and institutional affiliations. 
(c) (i) Open Access This article is licensed under a Creative Commons Attribution 4.0 International cc) License, which permits use, sharing, adaptation, distribution and reproduction in any medium or format, as long as you give appropriate credit to the original author(s) and the source, provide a link to the Creative Commons licence, and indicate if changes were made. The images or other third party material in this article are included in the article's Creative Commons licence, unless indicated otherwise in a credit line to the material. If material is not included in the article's Creative Commons licence and your intended use is not permitted by statutory regulation or exceeds the permitted use, you will need to obtain permission directly from the copyright holder. To view a copy of this licence, visit http://creativecommons.org/licenses/by/4.0/.

(C) The Author(s) 2020 